\title{
The Diagnosis \& Management of Orthopaedic Birth Trauma
}

\author{
Sarwar Ibne Salam ${ }^{1}$ \\ Swapan Kumar Paul ${ }^{2}$ \\ Florida Rahman ${ }^{3}$ \\ Md Khurshed Alam ${ }^{1}$ \\ Failey Elahi Milad ${ }^{4}$ \\ Md Mobarak Hossain ${ }^{1}$ \\ Bilkis Begum ${ }^{5}$
}

'Department of Orthopaedic \& Traumatology Dhaka Medical College Hospital Dhaka, Bangladesh.

${ }^{2}$ Department of Pediatric Surgery Dhaka Shishu (Children) Hospital Dhaka, Bangladesh.

${ }^{3}$ Department of Obstetrics \& Gynaecology Sir Salimullah Medical College \& Mitford Hospital Dhaka, Bangladesh

${ }^{4}$ Department of Neurosurgery National Institute of Neurosciences Dhaka, Bangladesh

${ }^{5}$ Department of Obstetrics \& Gynaecology Kumudini Women's Medical College Hospital Tangail, Bangladesh.

\section{*Correspondence to:}

Dr. Sarwar Ibne Salam Assistant Professor

Division of Paediatric Orthopaedics Department of Orthopaedic Surgery Dhaka Medical College Hospital Dhaka, Bangladesh.

Mobile: +8801819403408

E-mail: sarwarsalam@gmail.com

\begin{abstract}
Introduction: Fractures \& Orthopaedic trauma to the new born baby during birth are not uncommon. Immediate unavailability of an Orthopaedic surgeon adds to the embarrassment of the Obstetrician, and creates tension of the parents. Simple early measures can be taken to ease the situation. This paper is prepared with the intention of discussing some of the more common situations $\&$ their immediate management. Materials \& Methods: Few patients with different birth trauma were treated in Dhaka Medical College Hospital \& some other government \& non government hospitals during January 2009 to June 2014. Different types of fractures, epiphyseal separation, Obstetric brachial Plexus palsy, Congenital Muscular Torticolis were treated by traction, splinting, plasters, physiotherapy \& other conservative methods. Patients were followed up for long term assessment. Results: Results of fracture management were excellent with early union of all the cases. Soft tissue trauma, like Congenital Muscular Torticolis \& Obstetric brachial plexus palsy treatment yielded variable results owing to the depth of their involvement. Conclusion: Despite all the measures, trauma to the newborn baby still happens worldwide. Situation in Bangladesh is probably still worse. Early management of birth trauma is essential to avoid a lifelong disability. Immediate management may be started by the obstetrician before referring the patient, which will improve the final outcome.
\end{abstract}

Key words: Orthopaedics; Birth trauma; Diagnosis; Management.

\section{INTRODUCTION}

By definition Birth trauma is the "avoidable and unavoidable mechanical, hypoxic and ischemic injury affecting the infant during labour and delivery."

Orthopaedic birth trauma in the newborn is not uncommon. The incidence is related to many factors like, birth weight of the foetus, cephalo pelvic disproportion, diseases of the mother and also on the obstetrician's experience \& mode of delivery etc. Birth related trauma was suggested to be mostly associated with breech presentation, shoulder dystocia and delivery by forceps or other instrumentation procedure. Perlow et al reported an incidence of 6 per 1000 live birth of trauma related to birth ${ }^{1}$. Apart from this, in different studies head injury, brachial plexus injury, clavicle fractures, femoral fractures and spinal cord injuries have all been reported due to birth trauma ${ }^{2-14}$. Studies are few and far apart, which could assess the incidence of birth injuries in Bangladesh. In USA birth related injury Causes $2 \%$ of neonatal deaths and stillbirths \& 6-8 injuries per 1000 live births ${ }^{15-17}$.

This study was undertaken to evaluate the results of birth associated trauma in some govt. and non govt. hospitals \& orthopaedic department of Dhaka Medical College Hospital. 


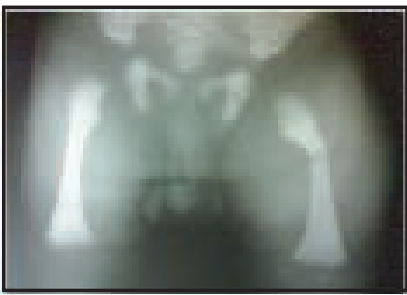

Figure 1a : Fracture femur due to birth trauma(2nd day)

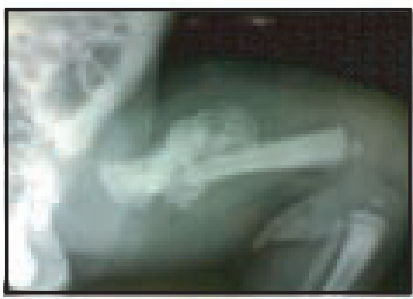

Figure 1c: Huge callus on 22nd day

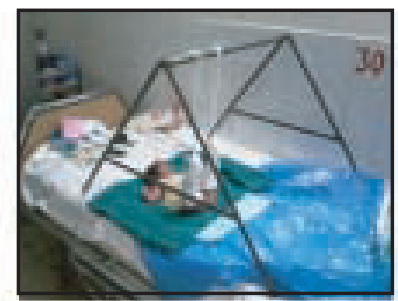

Figure $1 \mathrm{~b}$ : Being treated by Gallow's traction

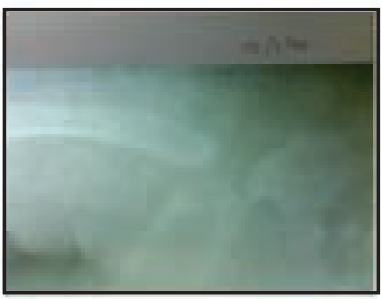

Figure 1d : Remodeled

Femur at 5 month

\section{MATERIALS \& METHODS}

We performed a prospective review of the patient's who would come to the orthopaedic department of Dhaka medical college hospital \& some other govt. \& non govt. hospitals during the period of January 2009 to June 2014 with birth related orthopaedic injuries. Patients with fractures and other visible deformity would come immediately for definitive treatment but some of the patients reported late due to ignorance or deformity developing late. Different types of fractures, epiphyseal separation, obstetric brachial Plexus palsy, congenital muscular torticolis, clavicle fracture etc. were treated by traction, splinting, plasters, physiotherapy \& other conservative methods. Some of the fractures, like clavicle fracture needed only assuring the parents, on the other hand femur fracture were treated by using Gallow's traction or Pavlik harness.

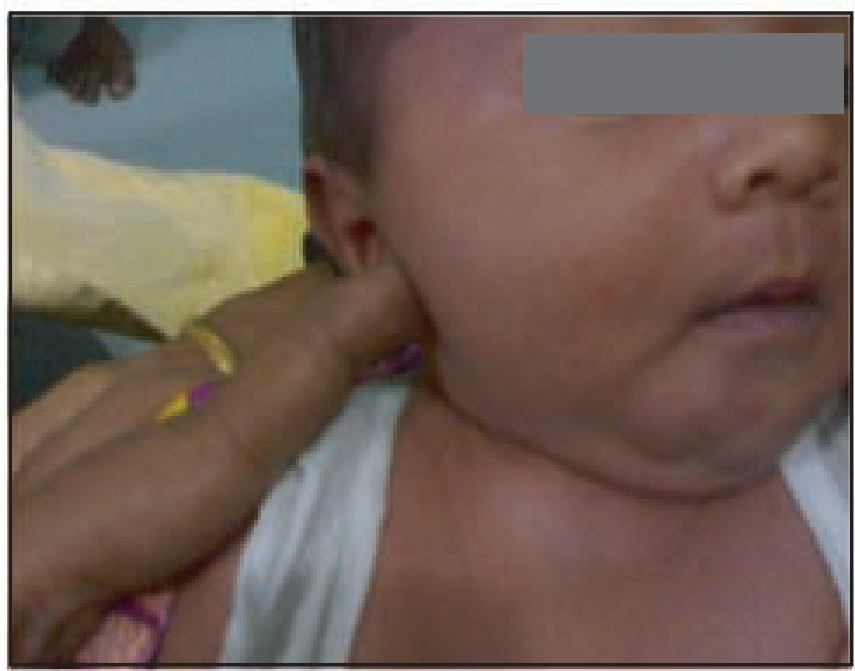

Figure 2 : Clavicle fracture due to birth trauma was detected 17 days after birth when a bump was seen on the right side of the shoulder. Good amount of callus was seen in X-ray.

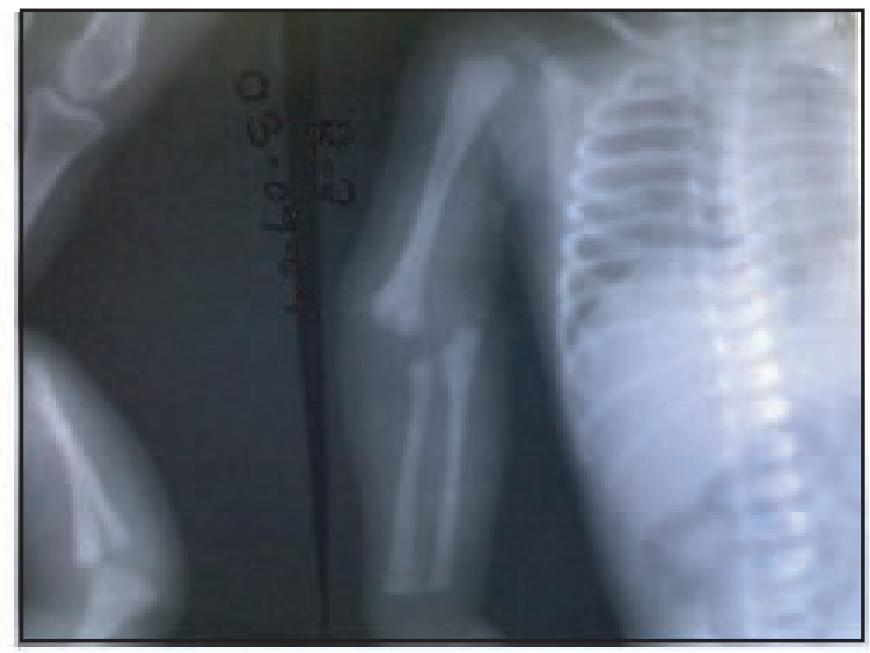

Figure 3 : X-ray on the 2ndday, distal Humeral epiphyseal separation due to birth trauma.

New born with impending Congenital muscular torticolis (CMT) were treated successfully with exercise only but late coming cases with full blown CMT needed surgery to correct the deformity. Obstetric brachial plexus palsy patients were treated with observation, physiotherapy or surgery. Patients were followed up for long time assessment.

\section{RESULTS}

A total of 31 patients, age ranging from 1 day to 9 years came with different types of orthopaedic birth trauma. All were below the age of 7 months except 7 patients. The average age was 2.25 years. 24 patients who had fractures came within 10 days of their birth, whereas the late coming 7 patients were either Obstetric brachial plexus palsy (OBPP) or Congenital muscular torticolis (CMT) cases. 13 (43\%) patients were boys \& $18(57 \%)$ were girls. Out of 31 deliveries, 12 (38\%) were delivered in the hospital \& $19(72 \%)$ were home delivery. The mode of delivery were, 4 (12\%) caesarean section \& 27 (88\%) vaginal deliveries. Among the vaginal deliveries there were 5 shoulder arrests, instrumentations were done in 6 cases, 5 had breech presentation \& 4 were macrosomic babies. 18(57\%) of the cases were primigravida. The average gestational age of the study group was 39 weeks (25-44 weeks). However the exact history of all of the home delivery cases were not available.

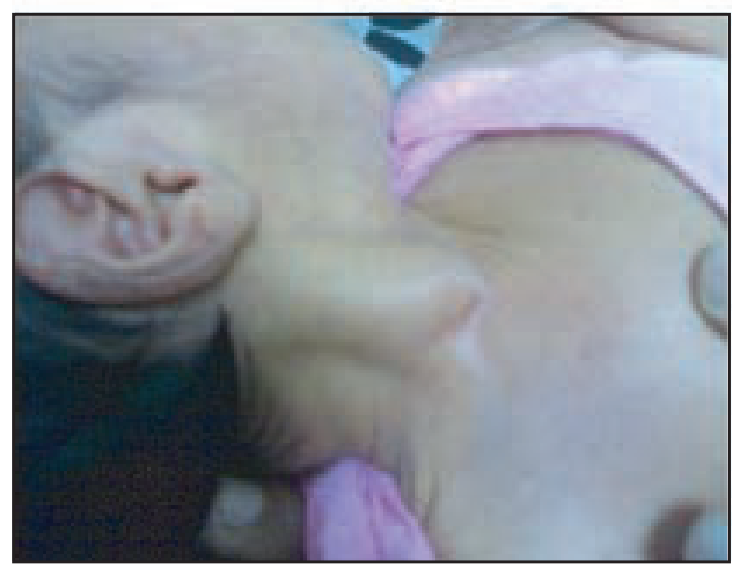

Figure $4: 13$ days old baby with right sternocleidomastoid muscle swelling due to birth trauma. 


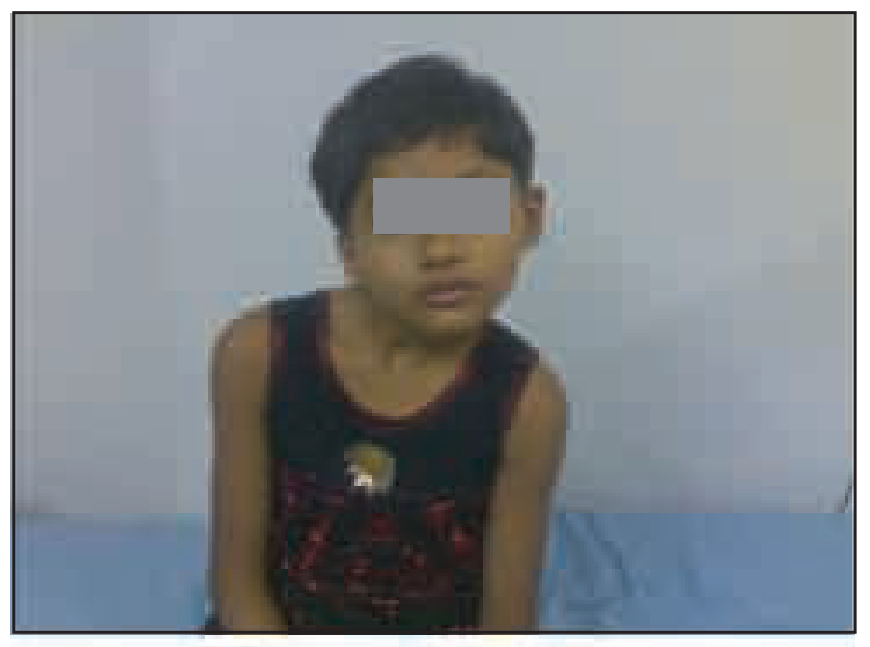

Figure 5a : 9 yrs old girl with full blown Congenital muscular torticolis

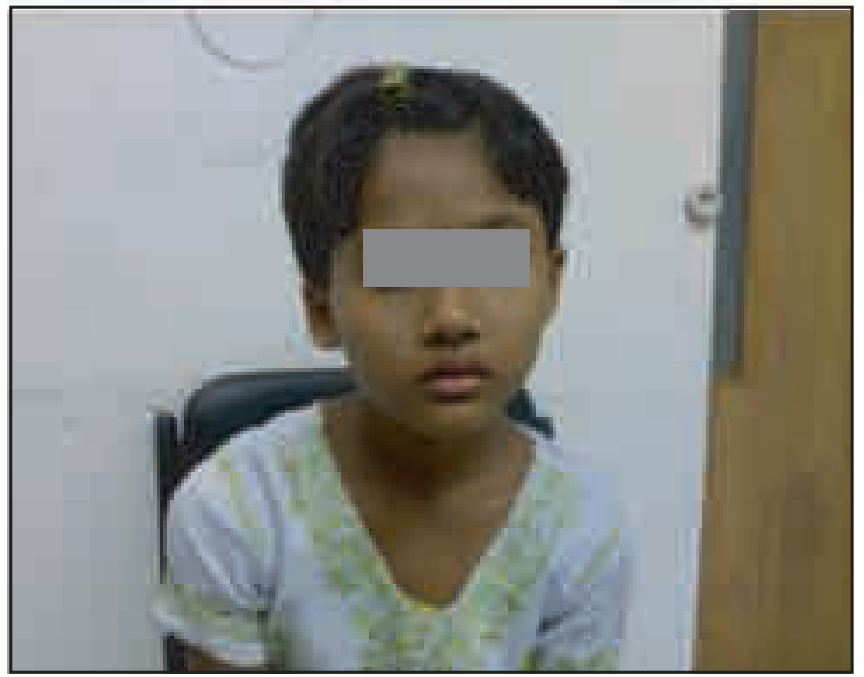

Figure 5b : After surgical correction

The average birth weight of the babies were $3.7 \mathrm{~kg}$, which is much higher than the average in Bangladesh. Birth weight of 12 babies who had home delivery could not be known due to their ignorance. Among them 4 were macrosomic, according to the history of the parents.

All the fractures united with traction, splinting, plasters or other form of immobilization. Some without any active treatment like the Clavicle fractures. The OBPP cases improved gradually but one of them needed derotation surgery of the humerus. 2 of the 5 CMT cases needed surgery but the 3 others were managed conservatively.

\section{DISCUSSION}

Birth process is a blend of compression, contractions, torques, $\&$ traction. Fetal size, presentation \& neurologic immaturity complicate this event causing tissue damage, edema, hemorrhage \& fracture in neonate. Obstetric instrumentation may induce injury or amplify the effects. Caesarean delivery is an acceptable alternative but does not guarantee an injury-free birth. Factors predisposing to injury include the following, primi gravida, cranio- pelvic disproportion (CPD), Prolonged or rapid labour, deep transverse arrest, oligohydramnios, abnormal presentation (breech), use of midcavity forceps or vacuum extraction, very low birth weight infant or extreme prematurity ,foetal macrosomia, versions and extractions, large foetal head \& foetal anomalies.

Early management of birth trauma is essential to avoid a lifelong disability. Immediate management may be started by the obstetrician before referring the patient, which will improve the final outcome. Sometimes applying a simple bandage or keeping the baby in certain position is mere enough. This study demonstrates a variety of birth related trauma patients who came to a teaching institution \& a specialized Paediatric orthopaedic clinic who were managed by various methods of treatment. It was evident from the study that babies born with higher birth weight \& delivery performed at home were common victims of birth trauma. Treatment results of various fractures were excellent but other deformities caused by orthopaedic birth trauma showed variable results due to their different depth of involvement. The study also shows that timely simple intervention of many of the cases may help to avoid difficult surgery at a later period. In this study, two of the CMT cases which had to be corrected by surgery later on.

Studies regarding the results of orthopaedic birth trauma management are only little available in the text \& literature. Wider study is necessary for better learning \& management.

\section{CONCLUSION}

Despite all the measures, trauma to the newborn baby still happens worldwide. Situation in Bangladesh is probably still worse. Adequate perinatal care, hospital delivery \& training of the personnel involved in perinatal care can reduce the birth trauma. It is recommended that every effort should be taken to decrease the incidence of birth injuries.

\section{DISCLOSURE}

All the authors declared no competing interest. 


\section{REFERENCES}

1. Perlow JH, Wigton T, Hart J, Strassner HT, Nageotte MP, Wolk BM. Birth trauma. A five-year review of incidence and associated perinatal factors. J Reprod Med. 1996; 41: 754-760.

2. Ecker JL, Greenberg JA, Norwitz ER, Nodel AS, Repke JT. Birth weight as a predictor of brachial plexus injury. Obstet Gynecol. 1997; 87: 643-647.

3. Gilbert WM, Nesbitt, TS, Danielsen B. Associated factors in 1611 cases of brachial plexus injury. Obstet Gynecol. 1999; 93: 536-540.

4. Sandmire HF, DeMott RK. Erb’s palsy causation: A historical perspective. Birth. 2002; 29: 52-54.

5. Nadas S, Reinberg O. Obstetric fractures. Eur J Pediatric Surgery. 1992; 2: 165-168.

6. Chez RA, Carlan S, Greenberg SL, Spellacy WN. Fractured clavicle is an unavoidable event. Am J Obstet Gynecol. 1994; 171: 797-798.

7. McBride MT, Hennrikus WL, Mologne TS. Newborn clavicle fractures. Orthopedics. 1998; 21: 317-319.

8. Morris S, Cassidy N, Stephens M, McCormack D, McManus F. Birth-associated femoral fractures: Incidence and outcome. J Pediatric Orthopedics. 2002; 22: 27-30.

9. Salomen IS, Uusitalo R. Birth injuries: Incidence and predisposing factors. Z Kinderchir. 1990; 45: 133-135.

10. Graham EM, Forouzan I, Morgan MA. A retrospective analysis of Erb's palsy cases and their relationship to birth weight and trauma at delivery. J Matern Med. 1997; 6: 1-5.

11. Jennett RJ, Tarby TJ, Kreiniek CJ. Brachial plexus palsy: An old problem revisited. Am J Obstet Gynecol. 1992; 166: 1673-1676.

12. Ouzolenion JG, Korst LM, Phelan JP. Permanent Erb palsy: A traction-related injury. Obstet Gynecol. 1997; 89: 139-141.

13. Hankins GD, Clark SL. Brachial plexus palsy involving the posterior shoulder at spontaneous vaginal delivery. Am J Perinatal. 1995; 12: 44-45

14. Dunn DW, Engle WA. Brachial plexus palsy: Intrauterine onset. Pediatr Neurol. 1985; 1: 367-369.

15. Levin MG, Holroyde J, Woods JR, Siddiqi TA, Scott M, Miodornick M. Birth trauma: Incidence and predisposing factors. Obstet Gynecol. 1984; 63: 792-795.

16. Walle T, Hartikainen-Sorri AL. Obstetric shoulder injury. Associated risk factors, prediction and prognosis. Acta Obstet Gynecol Scand. 1993; 72: 450-454.

17. McFarland LV, Raskin M, Daling JR, Benedetti TJ. Erb/Duchenne's palsy: A consequence of foetal macrosomia and method of delivery. Obstet Gynecol. 1986; 68: 784-788. 